\title{
Políticas de accountability na Educação Básica brasileira: um estudo do pagamento de docentes por desempenho
}

\author{
Accountability policies in Brazilian basic education: a study of payment per \\ teachers by performance \\ Políticas de accountability en la educación básica de Brasil: un estudio sobre el \\ pago por desempeño de los profesores
}

ANDRÉIA FERREIRA DA SILVA

Resumo: $\mathrm{O}$ artigo estuda o estabelecimento de iniciativas de avaliação externa e de pagamento de professores por desempenho, as finalidades e formas que vêm assumindo nas políticas subnacionais, com destaque para as medidas adotadas na rede de ensino de Campina Grande. Fundamenta-se em pesquisa bibliográfica e documental. O estudo discute os limites de tais políticas e seus desdobramentos para a educação brasileira.

Palavras-chave: Educação básica; políticas de accountability; pagamento de professores por desempenho.

\begin{abstract}
This article discusses the implementation of accountability policies in the Brazilian basic education. Studies the establishment of initiatives of external evaluation and the payment per teachers by performance, the purposes and ways that are assuming the sub-national policies, highlighting the measures adopted in Campina Grande school system. It is based on bibliographic and documentary research. The study discusses the limits of such policies and their consequences for Brazilian education.
\end{abstract}

Keywords: Basic education; accountability policies; payment per teachers by performance.

Resumen: Este artículo discute la implantación de políticas de accountability en la educación básica brasileña. Estudia el establecimiento de iniciativas de evaluación externa y del pago a los profesores por desempeño, los propósitos y formas que están asumiendo en las políticas sub nacionales, destacando las medidas adoptadas en el sistema escolar de Campina Grande. Se basa en la investigación bibliográfica y documental. El estudio discute los límites de dichas políticas y sus consecuencias para la educación brasileña.

Palabras clave: Educación básica; políticas de accountability; pago de profesores por desempeño. 


\section{INTRODUÇÃO}

O artigo tem como objetivo geral discutir as políticas de accountability na Educação Básica brasileira. Para alcançar esse propósito, analisa, inicialmente, o processo de implantação das iniciativas federais de avaliação externa e de responsabilização na Educação Básica. Em seguida, examina a instituição de políticas subnacionais de pagamento de professores por desempenho, as finalidades e as configurações que tais políticas vêm assumindo. Por fim, investiga as iniciativas de accountability adotadas na rede municipal de ensino de Campina Grande. O estudo fundamenta-se em pesquisa bibliográfica e documental. A pesquisa bibliográfica examinou a produção que trata da temática da avaliação em larga escala no país e da instituição de mecanismos de accountability, com o estabelecimento do uso dos resultados das avaliações com consequências fortes para a escola e seus profissionais, por meio, entre outros, do pagamento de professores por desempenho. A pesquisa documental analisou documentos legais e normativos referentes às iniciativas estandardizadas de avaliação e ao estabelecimento de mecanismos de responsabilização e de prestação de contas na Educação Básica brasileira e no município investigado.

De acordo com Sousa (2013), é difícil conhecer as iniciativas e as influências das políticas de avaliação nos municípios brasileiros, em decorrência da grande quantidade de municípios, mais de 5.560, e de sua diversidade e desigualdade. Essa situação contribui para o reduzido número de estudos que analisam os usos das avaliações em larga escala no âmbito municipal. Segundo a autora, nesses estudos, deve-se ter um cuidado redobrado em não generalizar os dados. Atentando para esse cuidado, o presente artigo discute as políticas de avaliação externa e de accountability implantadas em nível subnacional, tendo como foco o estudo das medidas instituídas no município paraibano de Campina Grande.

As iniciativas estaduais e municipais de avaliação externa e de pagamento de professores por desempenho estão se expandindo no país, fundadas nos princípios da competitividade, da meritocracia e da responsabilização. Nesse contexto, em um sentido mais amplo, o presente texto visa a contribuir para o alargamento da compreensão do estabelecimento dessas políticas no país e para a ampliação das discussões acerca de seus desdobramentos e riscos para a Educação Básica no Brasil. 


\section{AS POLÍTICAS DE AVALIAÇÃO EXTERNA E DE ACCOUNTABILITY NA EDUCAÇÃO BÁSICA BRASILEIRA}

As iniciativas de avaliação externa da educação escolar vêm-se fortalecendo no país, a partir dos anos 1990, em um contexto de redefinição da atuação do Estado marcado pelas teses neoliberais, que propõem a atuação estatal mínima no setor econômico e nas políticas sociais, defendendo a liberdade de mercado e opondo-se à noção de direitos sociais. As políticas públicas federais, a partir de então, vêm adotando o modelo de administração pública gerencial em que o Estado passa de executor para avaliador e regulador.

No contexto educacional, o Estado assume como uma de suas principais incumbências a avaliação da qualidade da educação. A partir de então, as iniciativas de avaliação em larga escala passam a ser compreendidas como mecanismo privilegiado para a aferição e a promoção da qualidade da educação. Nessa visão, os resultados do desempenho dos alunos nos testes padronizados são interpretados como evidência da qualidade da educação brasileira (SOUSA, 2013; LIRA, 2013).

Para Freitas (2007), o Estado brasileiro obteve a legitimação de sua proposta de uma avaliação centralizada, externa aos sistemas e às escolas, e pautada nos "princípios político-administrativos e pedagógicos que enfatizaram a administração gerencial, a competição e a accountability, na perspectiva de uma lógica de mercado" (p. 187). Esse modelo se caracteriza por uma regulação avaliativa centralizada no governo federal e orientada pelos princípios da administração gerencial que estimulam a competição entre as unidades escolares e os sistemas de ensino, combinada com a responsabilização dos agentes educacionais.

Segundo Freitas (2012), um sistema de responsabilização é constituído por três elementos: testes para estudantes, a divulgação pública do desempenho da escola e a instituição de recompensas e sanções ${ }^{1}$. Para ele, as recompensas e punições formam o caráter meritocrático desse sistema, mas não somente, já que a própria divulgação pública dos resultados da escola consiste, em si mesma, em uma forma de recompensa ou sanção. Desse modo, "a meritocracia é uma categoria [...] que perpassa a responsabilização" (p. 383).

O accountability no contexto educacional, para Brooke e Cunha (2011), constitui a associação entre resultados de aprendizagem e consequências para o distrito educacional, a escola, os professores ou os alunos. Os autores explicam

\footnotetext{
1 Nesse contexto, os professores são encorajados a melhorar cotidianamente sua produtividade, tornando-se um sujeito empreendedor do eu, que calcula a si mesmo e procura agregar novos resultados ao desempenho, A autenticidade do professor é sacrificada pela imagem que ele deve fabricar, demonstrar com os seus resultados, configurando sua performance. Para o autor, essa cultura traz incertezas, instabilidade e desprofissionalização para o professor (BALL, 2010).
} 
que "o grau de pressão que a autoridade educacional deseja aplicar ao processo de indução pode ser calibrado de acordo com o tipo ou seriedade das consequências" (p. 22).

De acordo com Passone (2014), as políticas de responsabilização na educação brasileira vêm contribuindo para camuflar os problemas educacionais, ao apontar os professores como os principais responsáveis pela oferta de um ensino de qualidade. Para o autor,

\footnotetext{
A responsabilização na educação básica brasileira vem ocorrendo em detrimento da melhoria de elementos estruturais relacionados ao processo educacional, tornandose apenas um procedimento de racionalização dos recursos existentes, sem aportar investimentos substanciais às escolas (PASSONE, 2014, p. 443).
}

Adotando a mesma compreensão, Novaes (2013) afirma que a avaliação do desempenho, no contexto brasileiro, foi pouco considerada como investimento, relacionando-se mais com a punição do que com o crescimento e a melhoria do trabalho docente.

Desde os anos 1990, as iniciativas de avaliação externa ganharam destaque no país com a institucionalização do Sistema de Avaliação da Educação Básica (SAEB) e a implementação do Exame Nacional do Ensino Médio (Enem). Em 1995, no governo do presidente Fernando Henrique Cardoso, o SAEB foi reorganizado, ampliando seu alcance. Em 2005, no governo de Luiz Inácio Lula da Silva, o SAEB passou por reformulação, sendo constituído, a partir de então, por duas avaliações, a Avaliação Nacional da Educação Básica (ANEB) e a Avaliação Nacional do Rendimento Escolar (Anresc). A ANEB, realizada por amostragem a cada dois anos, é aplicada em escolas públicas e privadas no $5^{\circ}$ e no $9^{\circ}$ anos do Ensino Fundamental e no $3^{\circ}$ ano do Ensino Médio, para avaliar o desempenho dos alunos. Os resultados da ANEB são divulgados por municípios e estados. A ANRESC, conhecida como Prova Brasil, é realizada a cada dois anos em todas as escolas públicas no $5^{\circ}$ e no $9^{\circ}$ anos do Ensino Fundamental. O resultado da Prova Brasil (desempenho) e a taxa de rendimento (aprovação e reprovação) compõem o Índice de Desenvolvimento da Educação Básica (Ideb). 
O Ideb foi criado, em 2007, como um dos eixos centrais do Plano de Desenvolvimento da Educação (PDE)². A Provinha Brasil também foi instituída, em 2007, no âmbito do PDE. No ano de 2009, o ENEM foi reformulado pelo MEC, que estabeleceu seu uso como processo seletivo unificado para as universidades públicas federais por meio do Sistema de Seleção Unificada (Sisu) ${ }^{3}$. Em junho de 2013, foi instituída a Avaliação Nacional da Alfabetização (ANA), que passou a compor o SAEB e se insere no âmbito do Pacto Nacional pela Alfabetização na Idade Certa (PNAIC). Essa avaliação é destinada a avaliar, de forma censitária, todos os alunos matriculados no $3^{\circ}$ ano do Ensino Fundamental e tem por objetivo avaliar a qualidade, a equidade e a eficiência dos alunos do ciclo de alfabetização das redes públicas e será aplicada, anualmente, por meio de provas de língua portuguesa e matemática (SILVA, 2013).

O novo Plano Nacional de Educação (PNE), aprovado em 25 de junho de 2014, que estabelece as metas e as estratégias para a educação no país para os próximos dez anos, incorporou os resultados das avaliações estandardizadas como instrumento de gestão dos sistemas e das escolas. Segundo o PNE 2014-2024, o Ideb deve constituir-se como instrumento de avaliação e fonte de informação acerca da qualidade da Educação Básica no país, bem como orientar as políticas públicas para essa etapa da educação (BRASIL, 2014).

Uma das estratégias definidas para propiciar o cumprimento da Meta 7 do PNE 2014-2024 diz respeito à formalização e à execução do Plano de Ações Articuladas (PAR). Esse Plano, instaurado pelo Ministério da Educação desde 2007, tem por base os resultados do Ideb e é constituído por quatro dimensões: gestão educacional; formação de professores e dos profissionais de serviço e apoio escolar; práticas pedagógicas e avaliação; e infraestrutura física

2 Como parte do PDE, o Decreto n. 6.094, de 24 de abril de 2007, que dispõe sobre a implementação do Plano de Metas Compromisso Todos pela Educação, define que a participação da União no Compromisso será pautada no apoio aos municípios, ao DF e aos estados, para a implementação de 28 diretrizes. Entre estas destacam-se, para o tema em estudo, a exigência de que os sistemas de ensino divulguem nas escolas e na comunidade os resultados do Ideb (BRASIL, 2007, art. $2^{\circ}$, inc. XIX), a inserção, nos planos de carreira, cargos e salários da ênfase no mérito e na avaliação do desempenho dos professores (BRASIL, 2007, art. 2. ${ }^{\circ}$, inc. XIII), a avaliação do docente em estágio probatório, de preferência, externa ao sistema educacional local (inciso XV) e o julgamento do mérito e do desempenho para nomeação e exoneração de diretor de escola (BRASIL, 2007, art. 2. ${ }^{\circ}$, inc. XVIII). Ao analisar essas diretrizes do Plano de Metas, Silva (2010) afirma que se "observa[...] nessas diretrizes a importância conferida à instituição de mecanismos de avaliação do desempenho do professor e também do gestor. A determinação e a regulamentação desses mecanismos, considerando a autonomia dos entes federados na organização de seus sistemas de ensino, cabem aos estados e municípios que, ao elaborarem os seus PAR, devem considerar as diretrizes estipuladas no Plano de Metas” (p. 427). No entanto, não se pode desconsiderar o papel indutor do governo federal na definição das políticas educacionais.

3 De acordo com o MEC, a reformulação do ENEM teve como objetivo induzir a reestruturação dos currículos do ensino médio. As universidades possuem autonomia e podem optar entre quatro possibilidades de utilização do novo ENEM como processo seletivo: como fase única, com o sistema de seleção unificada, informatizado e on-line; como primeira fase; combinado com o vestibular da instituição; e como fase única para as vagas remanescentes do vestibular (BRASIL, 2013a). 
e recursos pedagógicos. Ao analisarem a implementação do PAR, Rodrigues et al (2013) afirmam que o monitoramento da execução do PAR pelo governo federal, realizado por meio de visitas técnicas e acompanhamento on-line, "vem se configurando em um mecanismo de esvaziamento da autonomia dos municípios, no tocante ao planejamento educacional" (p. 203).

No que se refere aos resultados das iniciativas de avaliação externa no país, Bonamino e Sousa (2012) distinguem seu uso em três gerações. A primeira diz respeito às avaliações diagnósticas sem consequências diretas para a escola e para os currículos escolares, consideradas, pelas autoras, como de baixo risco. Tais iniciativas objetivam, apenas, monitorar a qualidade da Educação Básica, não instituindo mecanismos de competição já que não divulga notas por alunos ou por escolas. A segunda geração consiste nas avaliações cujos resultados são divulgados por escolas, municípios e estados, possibilitando mecanismos de responsabilização dos sujeitos envolvidos. Essas avaliações são consideradas como de responsabilização branda, porque possibilitam a comparação entre as escolas por meio da nota do Ideb. Na terceira geração são implantados, a partir dos resultados das avaliações, mecanismos de premiação e punição aos profissionais da educação e às escolas. Essa geração é considerada de alto risco, porque traz consequências fortes para os professores e gestores ao responsabilizá-los pelos resultados (Idem).

No Brasil, pode-se caracterizar o momento atual das políticas educacionais de avaliação como sendo de segunda e terceira gerações. O Ideb consiste em importante instrumento para a instituição de mecanismos de accountability, pois seu resultado é divulgado por escolas, municípios e estados e vem sendo utilizado por redes estaduais e municipais de ensino, como critério para premiação e punição das escolas e dos sujeitos nela envolvidos. Além do exposto, Sousa (2013) e Brooke e Cunha (2011) revelam que muitos estados criaram e passaram a utilizar sistemas próprios de avaliação da educação com base nas matrizes de referência do SAEB, contemplando, até mesmo, mecanismos de responsabilização com ampla divulgação dos resultados e incentivos simbólicos e financeiros para escolas, gestores, professores e, inclusive, para alunos. Segundo Bauer (2013), os professores passaram a ser incorporados às reformas educativas, através da responsabilização, em decorrência da compreensão de que eles seriam os responsáveis pela concretização das reformas na escola. De acordo com essa compreensão, a avaliação do desempenho do docente é defendida como alternativa para a melhoria do ensino e da aprendizagem dos alunos.

Conforme Brooke e Cunha (2011), as finalidades atribuídas pelas autoridades governamentais à criação de sistemas de avaliação são "muito abrangentes e, às vezes, ultrapassam a própria capacidade da avaliação educacional" 
(p. 20). Desse modo, tais instrumentos podem não conseguir captar as especificidades dos diferentes instrumentos e usos da avaliação e incluir categorias que estão fora de sua finalidade real. Os autores identificaram, em pesquisa realizada sobre os sistemas de avaliação instituídos nos estados brasileiros no ano de 2010, que os resultados das avaliações vêm sendo utilizados com as seguintes finalidades: 1. avaliar e orientar a política educacional; 2. informar as escolas sobre a aprendizagem dos alunos e definir as estratégias de formação continuada; 3. informar ao público os resultados obtidos pelas escolas; 4. alocação de recursos; 5. estabelecimento de políticas de incentivos salariais; 6 . servir como componente de avaliação docente; e 7. servir para a certificação de alunos e escolas (Idem).

No processo de implantação de políticas de incentivo salarial dos docentes no país, os autores afirmam a existência de duas gerações. A primeira geração consiste nas iniciativas da Nova Escola, do estado do Rio de Janeiro, o sistema de bônus salarial do estado de São Paulo, o Prêmio Escola do Novo Milênio, do estado do Ceará, e o bônus salarial para professores alfabetizadores do município de Sobral. Essas iniciativas foram criadas no ano de 2011. Tais políticas tiveram em comum a formulação de critérios para o pagamento coletivo de incentivos salarias aos profissionais das escolas, com base nas médias de desempenho dos alunos do ano anterior. A segunda geração consiste nas experiências mais recentes, tais como os sistemas de incentivos coletivos de Pernambuco, Minas Gerais, São Paulo e Espírito Santo. Esses sistemas incorporaram procedimentos mais sofisticados para a definição dos critérios e a avaliação da escola (BROOKE; CUNHA, 2011).

Em relação às políticas de incentivo salarial, Cassettari (2012) apresenta os três principais modelos de remuneração de professores por desempenho existentes no país: pagamento por mérito individual, bonificação com base no resultado das escolas e pagamento com base nos conhecimentos e habilidades dos professores. O pagamento por mérito individual, em geral com bônus financeiro, fundamenta-se na ideia de que premiar os professores que mais se destacam em avaliações individuais consiste em uma recompensa por seus esforços, além de estimular o conjunto do corpo docente a melhorar seu desempenho. De acordo com autora, esse foi o "primeiro modelo de remuneração por desempenho implantado no Brasil e, apesar de ainda ser utilizado, tem perdido espaço para iniciativas mais elaboradas" (p. 7).

No modelo de bonificação que tem como referência os resultados da escola, a premiação é conferida a todos os docentes e, em alguns casos, aos 
funcionários e até aos alunos ${ }^{4}$, das unidades escolares que alcançaram os objetivos previamente definidos. Nessa situação, a principal meta é elevar os resultados obtidos nas avaliações externas. Nesse modelo, há uma compreensão de que os resultados obtidos pela escola são consequência dos esforços de diferentes atores (Idem). Os prêmios concedidos podem consistir em materiais e em equipamentos escolares ou no pagamento de um adicional no salário dos professores. No caso da concessão de um prêmio aos docentes, "trata-se sempre de um bônus ao final da avaliação e não de um acréscimo salarial permanente, fazendo com que os professores tenham que reconquistar os seus prêmios ao final de cada processo avaliativo" (Idem, p. 8).

De acordo com a autora, o financiamento dessas iniciativas de bonificação "deve ser grande o suficiente para premiar todas as escolas que alcançarem os resultados desejados" (Ibidem). A autora destaca que a implantação desse modelo vem sendo feita de duas formas. A primeira consiste no estabelecimento de uma quantia predeterminada de recursos para o programa, sendo que o valor dos prêmios varia de acordo com o número de escolas premiadas. A segunda se refere à fixação de um valor dos prêmios com a limitação do número de escolas premiadas a partir de um ranking decrescente. Além disso, o financiamento dessas iniciativas deve "ser previsto por um longo período, para possibilitar que as escolas tenham tempo de tomar as medidas necessárias em vista de melhorar seus resultados" (CASSETTARI, 2012, p. 8).

As primeiras iniciativas de bonificação com base no desempenho das escolas premiavam inicialmente, conforme a autora, todos os professores das escolas com maiores desempenhos nas avaliações. A partir de 2008, as secretarias de educação passaram a conceder a premiação tendo como referência a combinação do desempenho dos alunos com indicadores do fluxo escolar, assimilando princípio similar ao do Ideb. De acordo com a autora em análise, esse modelo tem se expandido com bastante rapidez no país.

Ainda segundo a autora, o modelo do pagamento fundamentado nos conhecimentos e habilidades dos professores "remunera a aquisição, comprovada

\footnotetext{
$4 \quad$ No estado do Ceará, o Prêmio para os Alunos do Ensino Médio distribui laptop a todos os alunos que conseguem média 325 em Língua Portuguesa e 350 em Matemática no Sistema Permanente de Avaliação da Educação Básica do Ceará (SPAECE). Política semelhante foi implantada no município do Rio de Janeiro para os alunos que obtiveram os melhores resultados nas notas de Português e Matemática. Os cinco melhores alunos de cada disciplina dos dois anos avaliados foram premiados com uma bicicleta (BROOKE; CUNHA, 2011). No estado de Goiás e do Mato Grosso do Sul, as iniciativas de premiação de alunos das redes estaduais de ensino não têm relação entre a recompensa e o desempenho nas avaliações em larga escola em curso. Em Goiás, o Prêmio Poupança Aluno, que integra o Programa Renascer, concede uma vantagem pecuniária de $\mathrm{R} \$ 1.100,00$ (mil e cem reais) creditado na conta-poupança de titularidade dos alunos que obtiverem melhor rendimento acadêmico. Em Mato Grosso do Sul, foi criado o Programa Escola para o Sucesso, que concede prêmios, dinheiro, equipamentos ou materiais aos alunos que apresentarem melhor desempenho nas disciplinas, entre outras exigências. Para saber mais sobre essas iniciativas, consultar Araújo (2014).
} 
de diferentes maneiras, de determinados conhecimentos e habilidades", sendo, também, chamado de "pagamento por competências" (p.10). Para ela, o pagamento por conhecimentos e habilidades "introduz novos e mais diretos indicadores que possibilitam a vinculação do salário dos professores às competências consideradas necessárias a um bom exercício da profissão" (Idem, p. 8). Esse modelo de remuneração é o de mais recente implantação no Brasil, registrando as iniciativas da Bahia e São Paulo. Segundo a autora, "uma dificuldade que estes programas encontram é a definição de quais competências devem ser premiadas e, talvez ainda maior, a definição como elas serão verificadas" (Idem, p. 11) .

\section{AS POLÍTICAS DE ACCOUNTABILITY NA REDE MUNICIPAL DE ENSINO DE CAMPINA GRANDE/PB}

O município de Campina Grande localiza-se no planalto da Borborema e está distante $130 \mathrm{~km}$ de João Pessoa/PB, capital do estado da Paraíba. É o segundo maior município do Estado em população e possui o segundo maior PIB entre os municípios paraibanos, representando 15,63\% do total das riquezas produzidas na Paraíba. Destaca-se economicamente pela prestação de serviços e pelo comércio. Consiste em um polo formativo e tecnológico, por possuir cinco universidades, entre elas duas públicas, a Universidade Federal de Campina Grande (UFCG) e a Universidade Estadual da Paraíba (UEPB), com cursos na área de ciências humanas, de saúde e de tecnologias ${ }^{6}$.

Campina Grande possui, segundo dados do MEC/INEP (2011), população urbana de 366.375 habitantes e rural de 18.004 habitantes. A taxa de analfabetismo da população de 15 anos ou mais é de $17.10 \%$. A taxa de escolarização líquida no município no Ensino Fundamental (dos sete aos 14 anos) é de $82.79 \%$, abaixo da taxa do Estado, que é de 93.50\%, e no Ensino Médio (dos 15 aos 17 anos) é de 45,36 acima da taxa do Estado, que é de 37.70\% (BRASIL, 2011). A rede municipal de ensino de Campina Grande possui 122 unidades de Ensino Fundamental e 127 unidades de Educação Infantil. Conta com 868 docentes que atuam no Ensino Fundamental e 206 docentes na pré-escola, que atendem a 15.127 mil matrículas no Ensino Fundamental e 4.636 matrículas na pré-escola (Idem).

\footnotetext{
5 Cassettari (2012) informa que, para amenizar esse problema, "alguns programas adotam sistemas de certificação de professores como o principal mecanismo de verificação da aquisição de determinados conhecimentos e habilidades" (p. 11).

6 O Índice de Desenvolvimento Humano Municipal (IDH-M) de Campina Grande, no ano de 2013, foi de 0,720 , considerado um alto desenvolvimento humano, com 0,812 de longevidade, 0,702 de renda e 0,654 de educação. O município ocupa a posição 1301 no Brasil.
} 
Em 2007, as escolas municipais de Campina Grande obtiveram, no Ideb dos anos iniciais do Ensino Fundamental, o desempenho de 3.3 quando a meta estipulada era 3.2. No ano de 2009, obteve 3.8, sendo 3,5 a meta prevista e, no ano de 2011, obteve a nota 4.2, com meta estipulada de 3.9. Percebe-se que os índices das escolas municipais são superiores às metas projetadas; entretanto, tais resultados são baixos, quando comparados às médias do país: 4.0 no ano de 2007, 4.4 em 2009 e 4.7 em 2011 (BRASIL, 2013b).

Tendo como referência a pesquisa documental e, com o auxílio da pesquisa bibliográfica, a investigação identificou que as políticas de avaliação adotadas no país desde os anos 1990 têm interferido na dinâmica da Secretaria Municipal de Educação e Cultura de Campina Grande. Foi identificada no ano de 2013 a aprovação, pela Câmara de Vereadores do município, de duas leis relativas ao setor educacional tendo como referência os resultados do Ideb e a instituição de mecanismos de accountability educacional: a Lei n. ${ }^{\circ}$ 072, de 10 de abril de 2013, que institui o $14^{\circ}$ salário, e a Lei n. ${ }^{\circ} 5.372$, de 03 de dezembro de 2013, que torna obrigatória a divulgação do Ideb pelas escolas do município.

A Lei n. ${ }^{\circ}$ 072/2013 cria um mecanismo de pagamento coletivo de incentivos salarias aos profissionais das escolas com base nas médias de desempenho dos alunos do ano anterior. De acordo com a Lei, composta por quatro artigos, os trabalhadores da educação que elevarem o Ideb da escola no ano escolar, em pelo menos vinte por cento, receberão o décimo quarto salário, que deverá ser pago no final do mês de dezembro ${ }^{7}$ (CAMPINA GRANDE, 2013a, art. $1^{\circ}$ ). Observa-se que o $14^{\circ}$ salário deverá ser pago a todos os trabalhadores da escola, contemplando professores, gestores, pessoal da limpeza, da cozinha e porteiros, certamente com o objetivo de estimular e envolver todos os trabalhadores da escola no acompanhamento e na elevação do índice. Essa medida fundamenta-se na crença de que a busca pelo recebimento de um adicional salarial mobilizará os profissionais das escolas a se comprometerem e a se responsabilizarem pela melhoria do Ideb, que é compreendido, na política educacional em curso, como um indicador objetivo da qualidade da educação.

A Lei n. ${ }^{\circ}$ 072/2013 estipula, ainda, que, nos anos em que "não ocorrer a aplicação do projeto governamental Prova Brasil, o Poder Executivo Municipal é autorizado a estabelecer outro critério de avaliação para a concessão do décimo quarto salário" (Idem, art. $2^{\circ}$ ). É necessário destacar que a lei municipal, no artigo $2^{\circ}$, apresenta duas confusões ou imprecisões. A primeira, ao denominar a Prova Brasil projeto governamental; na verdade, a Prova faz parte do Sistema de Avaliação da Educação Básica (SAEB), que integra o sistema nacional de avaliação da

\footnotetext{
7 Nos anos 2013 e 2014, o pagamento do $14^{\circ}$ salário não foi feito até o final do mês de dezembro, como definido na lei, mas no ano seguinte.
}

518 - RBPAE - v. 32, n. 2, p. 509 - 526 mai./ago. 2016 
educação, que consiste em uma política educacional regulada por legislação federal. A segunda, ao confundir o ano de realização da Prova Brasil com o ano de divulgação dos resultados do Ideb. No ano em que ocorre a aplicação da Prova Brasil, não há a divulgação do Ideb. Desse modo, parece que a lei pretendeu definir o ano em que não ocorrer a divulgação dos resultados do Ideb e não da aplicação da Prova, visto que a elevação dos resultados do Ideb é que foi determinada como a referência para o pagamento do $14^{\circ}$ salário.

Merece destaque, também, que a Lei n. ${ }^{\circ}$ 072/2013 confere à Secretaria de Educação e Cultura, no ano em que não ocorrer a divulgação dos resultados do Ideb pelo INEP/MEC, a definição de "outro critério de avaliação" para a concessão do bônus financeiro (Ibidem). Entretanto, não estabelece os princípios que devem ser considerados para tal. É interessante observar que, na definição desses critérios, a Secretaria de Educação e Cultura não conta sequer com o subsídio dos propósitos que justificaram a criação do bônus, considerando que não constam, da Lei, as finalidades ou os objetivos de sua instituição.

Na implantação da Lei n. ${ }^{\circ}$ 072/2013, o município de Campina Grande não definiu um valor predeterminado de recursos para o pagamento do bônus, situação em que o valor dos prêmios seria modificado de acordo com o número de escolas premiadas, fazendo com que quanto mais escolas atingissem a porcentagem do Ideb prevista, menor o valor do prêmio. Também não foi fixado um valor total dos prêmios, definindo antecipadamente o número de escolas a ser contemplado. O não estabelecimento dessas referências faz com que a concessão da recompensa careça de um parâmetro fixo para a definição das escolas a serem contempladas pelo prêmio. Desse modo, coube à Secretaria de Educação e Cultura o estabelecimento do número de escolas a receberem o bônus para a efetivação de seu pagamento.

Referente aos anos de 2013 e 2014, o município pagou o décimo quarto salário somente aos profissionais de três unidades educacionais, compreendendo duas escolas de Ensino Fundamental e uma creche. Em relação a essa situação, duas questões podem ser levantadas. A primeira consiste no fato de que, no ano de 2013, mais escolas além das duas contempladas com o décimo quarto salário atingiram a exigência estipulada na lei da elevação do Ideb em, no mínimo, 20\% ${ }^{8}$, mas não receberam o prêmio.

É importante destacar o número reduzido de escolas contempladas com o pagamento do décimo quarto salário nos anos indicados. Considerando um total de 122 unidades de Ensino Fundamental existentes no município, somente duas

$8 \quad \mathrm{O}$ artigo $1^{\circ}, \sqrt{ } 2^{\circ}$, da Lei n. ${ }^{\circ}$ 072/2013 prevê que "Para obtenção do décimo quarto salário, o percentual de $20 \%$, descrito no caput do artigo, terá tolerância máxima de até cinco por cento na elevação do índice do Ideb" (CAMPINA GRANDE, 2013a). 
instituições receberam o bônus, o que equivale a apenas 1,64\% das escolas. Desse modo, constata-se que o critério referente ao ano de 2013 efetivamente adotado na rede municipal de ensino analisada não consistiu no pagamento do décimo quarto salário aos profissionais das escolas em que os resultados do Ideb no ano escolar foram elevados, em pelo menos $20 \%$, conforme estabelecido na Lei n. ${ }^{\circ} 072 / 2013$, mas na concessão do bônus aos profissionais das duas escolas municipais que mais elevaram o Ideb. Esse critério consiste na negação do princípio estabelecido na lei, que não limita o número de escolas a receberem o prêmio. Da forma como foi implantado, o décimo quarto salário pode, por um lado, ampliar a desconfiança e a competição entre as escolas para a obtenção da premiação a ser concedida a duas unidades de ensino e, por outro, gerar o desinteresse pelo prêmio devido à dificuldade para sua obtenção. Tal situação pode ser agravada pela falta de clareza e o desconhecimento dos critérios adotados para sua concessão, sobretudo nos anos em que não há a divulgação dos resultados do Ideb.

A segunda questão refere-se à concessão do bônus para uma instituição de Educação Infantil, revelando o descumprimento da própria lei municipal, visto que o único critério estabelecido para o seu pagamento tem como referência a aumento do Ideb e somente às instituições que oferecem o Ensino Fundamental se aplica tal índice, visto que seus alunos, matriculados no $5^{\circ}$ e no $9^{\circ}$ anos, realizam a Prova Brasil. Desse modo, com base nas definições contidas na Lei n. ${ }^{\circ}$ 072/2013, não é possível justificar o pagamento dessa bonificação aos profissionais que atuam em instituições de Educação Infantil.

A Lei $n^{\circ} 5.372 / 2013$ relaciona-se mais diretamente ao princípio da prestação de contas da escola à sociedade ao instituir a obrigatoriedade de as escolas municipais divulgarem os resultados do Ideb. De acordo com a lei, constituída por três artigos, tais notas deverão ser expostas em lugar visível e acessível a todos no âmbito escolar (CAMPINA GRANDE, 2013b, art. $1^{\circ}$ ). A lei estabelece que "a divulgação por parte da escola do Município deverá ser feita por meio de placa padronizada a ser afixada na entrada da escola, de forma que fique visível aos transeuntes em via pública" (Idem, art. $2^{\circ}$ ). É importante registrar que não constam da lei as finalidades ou os objetivos da obrigatoriedade da divulgação dos resultados do Ideb nas escolas.

A Lei n ${ }^{\circ} 5.372 / 2013$ estabelece, ainda, que a placa deverá conter as seguintes informações: síntese explicando o que representa o Ideb, o valor obtido pela escola, utilizando escala de 0 a 10, a meta estabelecida pelo MEC e o valor da média do Ideb apurado nas escolas municipais (Idem, art. $3^{\circ}$ ). Essas informações permitiriam a comparação entre o índice alcançado pela escola, a meta prevista e a média das escolas da rede municipal de ensino, possibilitando a identificação de sua situação. A exposição dos resultados do Ideb definida na lei objetiva, 
certamente, tornar público o desempenho das instituições de ensino, mobilizar a comunidade local e a sociedade mais ampla para o acompanhamento e a cobrança dos profissionais da escola para assegurar a elevação dos índices obtidos.

A aprovação das duas leis revela a importância que a avaliação externa e o Ideb vêm assumindo para a rede municipal de ensino de Campina Grande. O município vem utilizando os resultados do índice instituído pelo governo federal para estabelecer o pagamento por desempenho, mecanismo de responsabilização, de premiação e de punição dos professores, dos gestores e dos demais trabalhadores da educação.

Desse modo, vêm sendo adotadas pela SEDUC de Campina Grande políticas de monitoramento e de responsabilização das escolas e dos profissionais da educação pelos resultados obtidos, fundamentados no modelo gerencial, marcado pelo estabelecimento externo de metas a serem cumpridas e pela premiação por seu alcance.

\section{CONSIDERAÇÕES FINAIS}

A pesquisa permitiu identificar que o município de Campina Grande vem utilizando, desde 2013, os resultados do Ideb para o estabelecimento de uma política de incentivos salariais aos professores, gestores e demais trabalhadores das escolas. Desse modo, constituiu um mecanismo de pagamento por desempenho dos profissionais que atuam na escola.

A aprovação, nesse município, das Leis n. ${ }^{\circ}$ 072/2013 e n. ${ }^{\circ}$ 5.372/2013, que instituíram, respectivamente, o décimo quarto salário e a exigência da divulgação, em local visível nas instituições de ensino, dos resultados do Ideb, caracteriza-se pela inauguração do uso dos resultados da avaliação com consequências fortes para as escolas e seus profissionais, alcançando a terceira geração de iniciativas de avaliação. Nessas leis prevalece uma concepção de responsabilização dos profissionais da educação pelos resultados obtidos nos exames e de prestação de contas à sociedade que se constitui como mecanismos de implantação do accountability educacional.

Ao implantar o pagamento do décimo quarto salário, o município de Campina Grande adota um mecanismo de responsabilização com consequências fortes, ao vincular o pagamento de um bônus aos resultados obtidos nas avaliações estandardizadas e instituir uma diferenciação de rendimentos entre os trabalhadores da educação de sua rede. Essa diferenciação situa-se em dois níveis: primeiro, entre as etapas de ensino sob a responsabilidade do município, a Educação Infantil e o Ensino Fundamental, visto que os profissionais da primeira, segundo a Lei n. ${ }^{o}$ 072/2013, estão excluídos da possibilidade do recebimento desse 
adicional; e, segundo, entre os docentes do Ensino Fundamental que receberão e os que não receberão o bônus.

De acordo com Cassettari (2012), os programas com essas características utilizam, em geral, como principal critério para a distribuição do bônus o resultado das escolas nos sistemas de avaliação em larga escala. Tal critério é considerado como objetivo, o que, para alguns autores, é considerado como um "argumento positivo em favor da utilização desse modelo de avaliação" (p. 8). Entretanto, para outros autores, a vinculação da remuneração dos professores aos resultados nos sistemas de avaliação externa

\footnotetext{
Pode incentivar uma série de comportamentos questionáveis que não contribuem para a melhoria da qualidade da educação, dentre eles: a seleção e exclusão de alunos, a fraude, a concentração dos melhores professores em algumas escolas, a redução do currículo ao que é cobrado nas provas etc (Idem, pp. 8-9).
}

Os seguintes "problemas na hora da aplicação prática das regras" das políticas de incentivos salarias são apontados por Brooke e Cunha (2011, p. 50): as escolas nem sempre aplicam as provas aos alunos mais fracos para não reduzir suas médias, as instituições de ensino passam a se preocupar menos com as séries que não são avaliadas, a ocorrência da "transferência branca" de alunos com baixo desempenho para outras escolas, além da insatisfação dos profissionais de ensino pela pressão criada em torno do prêmio? .

Por sua vez, Araújo (2014, p. 110) afirma que a recompensa e o reconhecimento público pelos desempenhos na obtenção de resultados “naturaliza a ideia de que o 'sucesso' da escola centra-se na sua própria capacidade de superação e de avanço, enfatizando a responsabilidade dos profissionais da educação e da gestão escolar pela geração das melhorias, desconsiderando as condições materiais das escolas e o nível socioeconômico dos alunos, entre outros.

Em relação à valorização salarial dos professores com a adoção de políticas de pagamento por desempenho, argumento utilizado pelos defensores dessa iniciativa, é possível verificar o caráter descontínuo de tais bonificações, visto que não são incorporadas aos salários, estão condicionadas ao alcance das metas previstas e à disponibilidade de recursos dos governos estaduais e municipais. Tais situações revelam o reduzido impacto dessa política na elevação dos salários de professores e demais trabalhadores da educação.

As escolas brasileiras, segundo Gatti (2013), necessitam de uma série de investimentos para que possam superar seu caráter de precariedade. Desse modo, a implantação de políticas de bonificação sem a melhoria dessas condições, não

9 Essas observações referem-se à análise do programa Escola Nota 10 implantado no estado do Ceará. Para saber mais sobre as políticas de avaliação externa no Ceará consultar Brooke e Cunha (2011).

522 - RBPAE - v. 32, n. 2, p. 509 - 526 mai./ago. 2016 
consegue valorizar o professor, pois a valorização da docência está atrelada à melhoria das condições de trabalho, das condições salariais e da carreira, dentre outros. Estes são os desafios que necessitam ser enfrentados pelas políticas educacionais no país e não a transferência da responsabilidade por tal situação aos profissionais que atuam na escola, como pode ser observado nas políticas de accountability educacional em curso no país.

\section{REFERÊNCIAS}

ARAÚJO, Caroline Silva. Desempenho e recompensa: as políticas das Secretarias Estaduais de Educação. Goiânia: GO. 2014. 125p. Dissertação (Mestrado em Educação) - Universidade Federal de Goiás, Goiânia, 2014.

BALL, Stephen J. Performatividades e fabricações na economia educacional: rumo a uma sociedade performativa. Educação e Realidade, p. 37-55. maio/ ago. 2010. Disponível em: <http://seer.ufrgs.br/index.php/educacaoerealidade/ article/view/15865/9445>. Acesso em: 15 mar. 2015.

BAUER, Adriana. Avaliação de desempenho de professores: pressupostos e abordagens. In.: GATTI, Bernadete A. (org.). O trabalho docente: avaliação, valorização, controvérsias. Campinas, SP: Autores Associados; São Paulo: Fundação Carlos Chagas, 2013. p. 5-70.

BONAMINO, Alicia; SOUSA, Sandra Zákia. Três gerações de avaliação da Educação Básica no Brasil: interfaces com o currículo da/na escola. Educação e Pesquisa, São Paulo, v. 38, n. 2, p. 373-388, abr./jun. 2012. Disponível em: < http://www.scielo.br/pdf/ep/v38n2/aopep633.pdf >. Acesso em: 23 fev. 2014.

BRASIL. Lei $\mathbf{n}^{\mathbf{0}} \mathbf{1 3 . 0 0 5}$, de 25 de julho de 2014. Aprova o Plano Nacional de Educação - PNE e dá outras providências. Disponível em: < http://www.planalto. gov.br/ccivil_03/_Ato2011-2014/2014/Lei/L13005.htm>. Acesso em: 21 ago. 2014.

. Instituto Nacional de Estudos e Pesquisas Educacionais Anísio Teixeira.

Novo Enem. (2013a). Disponível em: <http://portal.mec.gov.br/index. php?option $=$ com_content $\&$ view $=$ article $\& i d=13318 \&$ Itemid $=310 \& m s g=1>$. Acesso em: 14 jun. 2015. 
Instituto Nacional de Estudos e Pesquisas Educacionais Anísio Teixeira. Ideb resultados e metas. 2013b. Disponível em: <http://ideb.inep.gov.br/ resultado/resultado/resultado.seam?cid=3367259> Acesso em: 19 ago. 2015.

. Ministério da Educação. Indicadores demográficos e educacionais. 2011. Disponível em: < http://ide.mec.gov.br/2014/municipios/relatorio/ coibge/2504009>. Acesso em: 21 ago. 2015.

Presidência da República. Decreto n. ${ }^{\mathbf{6}}$ 6.094, de 24 de abril de 2007. Dispõe sobre a implementação do Plano de Metas Compromisso Todos pela Educação. Brasília, DF, 2007. Disponível em: < http://portal.mec.gov.br/index. php?option $=$ com_content $\& v i e w=$ article $\& i d=153:$ legislacao $\&$ catid $=98$ :par plano-de-acoes-articuladas\&Itemid=366>. Acesso em: 6 jun. 2015.

BROOKE, Nigel; CUNHA, Maria Amália de A. A avaliação externa como instrumento da gestão educacional nos estados. Estudos \& Pesquisas Educacionais, São Paulo, v. 2, p. 17-79. 2011.

CAMPINA GRANDE. Lei $\mathbf{n}^{\mathbf{0}} \mathbf{0 7 2}$, de 10 de abril de 2013. Institui o décimo quarto salário dos profissionais da educação da rede pública municipal e dá outras providências. Semanário Oficial n. ${ }^{\circ}$ 2.338, 2013a. Campina Grande.

Lei n ${ }^{\mathbf{0}} \mathbf{5 . 3 7 2}$, de 03 de dezembro de 2013. Torna obrigatória a divulgação do Ideb por parte das escolas do Município na forma como especifica e dá outras providências. Semanário Oficial n. ${ }^{\circ}$ 2.338, 2013b. Campina Grande.

CASSETARI, Nathália. Principais modelos de remuneração por desempenho para professores no Brasil. 17p. Disponível em: <www.anpae.org.br/ iberoamericano2012/Trabalhos/NathaliaCassettari_res_int_GT2.pdf>. Acesso em: 15 mar. 2015.

FREITAS, Dirce Ney. A avaliação da educação básica no Brasil: dimensão normativa, pedagógica, e educativa. Campinas: Autores Associados, 2007.

FREITAS, Luiz Carlos de. Os reformadores empresariais da educação: da desmoralização do magistério à destruição do sistema público de educação. Educação \& Sociedade. v. 33, n. 119, p. 379-404. abr./jun. 2012. 
GATTI, Bernadete A. Valorização da docência e avaliação do trabalho docente: o papel da avaliação participativa em um contexto institucional. In.: (org.). $\mathbf{O}$

trabalho docente: avaliação, valorização, controvérsias. Campinas, SP: Autores Associados. São Paulo: Fundação Carlos Chagas, 2013. p. 153-176.

LIRA, Patrícia Rocha de Brito. A atuação do governo federal na disseminação da cultura do desempenho na educação básica brasileira (1995-2012). 2013. 222p. Dissertação (Mestrado em Educação) - Universidade Federal da Paraíba UFPB, João Pessoa. 2013

NOVAES, Gláucia Torres Franco. Padrões de desempenho na avaliação docente e profissionalidade docente. In.: GATTI, Bernadete A. (org.). O trabalho docente: avaliação, valorização, controvérsias. Campinas, SP: Autores Associados; São Paulo: Fundação Carlos Chagas, 2013. p. 109-152.

PASSONE, Eric Ferdinando Kanai. Incentivos monetários para professores: avaliação, gestão e responsabilização na Educação Básica. Cadernos de Pesquisa. v. 44, n. 152, p. 424-448, abr./jun. 2014. Disponível em: <http://publicacoes.fcc. org.br $/$ ojs $/$ index.php?journal $=$ cp\&page $=$ article\&op $=$ view $\&$ path $\% 5 B \% 5 \mathrm{D}=27$ 60\&path $\% 5 B \% 5 \mathrm{D}=2740>$. Acesso em: 6 ago. 2014

RODRIGUES, Melânia Mendonça et al. Planos de ações articuladas (PAR) em municípios paraibanos: alguns estudos. In: SILVA, Andréia Ferreira da; RODRIGUES, Melânia Mendonça (Orgs.). Índice de Desenvolvimento da Educação Básica (Ideb): avaliação da educação, organização escolar e trabalho docente em escolas municipais do Estado da Paraíba. Campina Grande: EDUFCG, 2013. p. 197- 215.

SILVA, Andréia Ferreira da. Políticas de avaliação em larga escala no Brasil: princípios, implantação e riscos. In: ;; RODRIGUES, Melânia Mendonça (Org.). Índice de Desenvolvimento da Educação Básica (Ideb): avaliação da educação, organização escolar e trabalho docente em escolas municipais do Estado da Paraíba. Campina Grande: EDUFCG, 2013. p. 17- 30.

Plano de desenvolvimento da educação: avaliação da educação básica e desempenho docente. Revista Inter-Ação, Goiânia, v. 35, n. 2, p. 415-435, jul./ dez. 2010. Disponível em: < http://www.revistas.ufg.br/index.php/interacao/ issue/view/950/showToc >. Acesso em: 15 maio. 2015. 
SOUSA, Sandra Zákia. Avaliação Externa e em Larga Escala no Âmbito do Estado Brasileiro: Interface de Experiências Estaduais e Municipais de Avaliação da Educação Básica com Iniciativas do Governo Federal. In: BAUER, Adriana; GATTI, Bernadete A. (Org.). Vinte e cinco anos de avaliação de sistemas educacionais no Brasil. Florianópolis: Insular, v. 2. 2013. p. 61-85.

ANDRÉIA FERREIRA DA SILVA é Doutora em Educação pela Universidade Federal Fluminense. Professora Associada da Universidade Federal de Campina Grande/PB e docente permanente do Programa de Pós-Graduação em Educação/UFCG. E-mail: silvaandreia@uol.com.br

Recebido em outubro de 2015

Aprovado em novembro de 2015 